\title{
Amplifying Silenced Voices Through Micro- and Small-Press Publishing
}

\author{
Jodie Lea Martire ${ }^{1} \mathbb{D}$
}

Accepted: 2 March 2021 / Published online: 16 April 2021

(c) Springer Science+Business Media, LLC, part of Springer Nature 2021

\begin{abstract}
This research uses exploratory, mixed-method case studies to explore the relationship between Australian micro- and small presses (MSPs), their publishing and promotion of writers of difference (WODs), and the relationship to Couldry's (2010) concept of voice. Through structured interviews with two publishing houses and their WODs, I (a) identified MSPs' strategies for publishing and promoting silenced and neglected writers, thus facilitating the expression of voice; and (b) learned how MSPs' authors respond to their publishers' efforts to promote voice, and what publishing strategies they suggest for the industry. This research offers a novel contribution to publishing studies and communication for social change.
\end{abstract}

Keywords Small press $\cdot$ Micro-press $\cdot$ Independent publishers $\cdot$ Diversity $\cdot$ Voice Australia

\section{Introduction}

Australian media ownership is among the world's most concentrated [15], while our publishing industry is dominated by the (current) "Big Five" transnationals plus locally owned Allen \& Unwin [13]. Compared to the $87 \%$ market share of the major players, Australia's micro- and small presses held just 6.8\% in September 2019 (Nielsen [37]. In an industry sliding inexorably toward monopolies, mainstream publishing's focus on bestsellers is widely understood to have led "to the limitation of smaller, more diverse voices" ([43], 90), whereas micro- and small presses (MSPs) "love to provide a location for writing that doesn't or can't find a voice in the mainstream media" [19], 48).

Mainstream publishers do publish "diverse" voices [49]. Writers of difference (WODs) have been published with great results, earning prizes, fans and financial independence through their work: this is the case of N.K. Jemisin, a Black woman

Jodie Lea Martire

j.martire@uqconnect.edu.au

1 The University of Queensland, PO Box 6226, St Lucia, QLD 4067, Australia 
sci-fi/fantasy writer. However, as the \#PublishingPaidMe scandal revealed, Jemisin's publisher (Hachette-owned Orbit) only paid her a US\$25,000 advance for each title in her Broken Earth trilogy - even after the first volume won the coveted Hugo Award. In the same period, white male sci-fi writers without a Hugo were earning six-figure advances $[16,25]$. Beyond merely publishing WODs, these writers must be treated with respect throughout the process-which, as I will show, MSPs specifically do.

Australia is a nation rich in languages, cultures and human experiences, but that wealth cannot be found in our published works. In lieu of comprehensive statistics for "diversity" in Australian publishing, we hear a chorus of non-mainstream writers protesting their exclusion and that of their communities: see Kwaymullina [28] on Indigenous writing; McGaughey [34] on Torres Strait Islander work; Cahill [8] on migrant writers; Wood [61] on Asian literary identity; Hoge [23] on disabled writers; queer writers in Binks [3]; and Kon-yu [27] on intersectionality.

The call of these writers has been neglected for too long. If MSPs do enable silenced voices—or voice, ${ }^{1}$ in Couldry's [11] term-we must understand why and how, so their methods can be publicised, adopted by like-minded peers and thus create a richer range in Australian publishing. To date, there has been little investigation of MSPs' strategies to effectively publish such voices. More importantly, nonmainstream writers published by MSPs have not been asked for their opinions on the strategies used to amplify their voices, by their publishers or the book industry as a whole.

This research was therefore undertaken specifically to investigate MSPs' tools, techniques and tactics used to connect disregarded voices with broader audiences. Using a mixed-method comparative case study, I researched the work of two Australian MSPs-Spinifex Press and Wild Dingo Press-through documentary analysis, structured interviews and participant observation (with Spinifex); I complemented this with structured interviews with two authors published by each press. No small-press research in Australia or the Anglosphere has taken this 360-degree approach.

This research also endeavours to situate small-press publishing within communication for social change. I consider the MSPs' work against Couldry's concept of voice, and contend that MSPs' publishing mission can significantly enrich Australia's public sphere and strengthen the democratic representation of voices unheard in Australian culture and media.

I refer to "difference" rather than "diversity". "Diversity" implies variance from and inferiority to dominant traits [9], while "difference" removes the latter judgement. Accordingly, I also prefer Bobis" [4] term "writers of difference" to "marginalised writers", despite the latter's current widespread use by emerging writers (e.g. [29].

${ }^{1}$ Couldry's voice appears in italics, to distinguish the theoretical term from other uses. 


\section{Literature Review}

MSPs are almost universally praised for publishing neglected and under-represented writers [31]. Australian MSPs have been the subject of considerable study in the last decade, but little of this examined their publishing motivations, dealings with under-represented writers or relationship to voice. Industry studies document MSPs' status (e.g. [54], and several studies considered MSPs' relationships with specific genres (e.g. romance in [14]), yet without focussing on how creators are chosen and promoted.

\section{Publishers and their Publishing Strategies}

An early profile of independent Australian presses (mostly MSPs) provides a useful summary of publishers' survival strategies [41]. Independents work at the frontier, are highly cooperative with each other and industry bodies, and publish in a specialist niche. They take risks, publish for quality and with a long-term focus, and are committed to new and Indigenous writing. This, plus a valuation of culture over commerce, are strongly driven by the presses' principles.

The most-relevant small-press studies were conducted by Ramdarshan Bold [42-43] in England and North America. In her 27 publisher interviews, Ramdarshan Bold asked whether they believed they could "help to promote and preserve regional cultures and identities" and "maintain diversity in cultural output". Both cohorts focused on niche or regional work, placed a high value on author relationships, and actively acquired work by under-represented creators. This work supports MSPs' commitment to voice, with "an overwhelming consensus that all independent publishers-no matter where they were based and what size of company they were-played an important role in protecting and making visible non-mainstream work" ([42], 46).

One important study examined how five Australian publishers (including smaller and socially committed presses) publish writers with educational and class disadvantages [7]. Despite most having an explicit commitment to publishing excluded writers, few opportunities for mentoring, programmes and prizes were offered to any except Indigenous writers. For the $40 \%$ of Australians who can't read well enough to enjoy a standard novel (36), participation in publishing and the public sphere can be impossible without ghostwriters or co-writers.

Stewart [52] provides a unique comparison for this research in documenting how 47 independent presses in six countries (including Australia) address the "diversity deficit":

hosting readings specifically for BAME and LGBTQIA groups, those with mental health issues, the homeless; creating screen-reader adaptable books ...; and publishing anthologies of poems written by deaf and disabled authors.... offering paid internships to encourage those not able to work for free; inviting younger writers and more women onto editorial boards; ... curating literary events whose invitees are not the usual crowd; pushing submissions from 
BAME groups to the front of the "slush pile", and openly inviting submissions-on the website platform-from under-represented groups. (20)

A useful study by Poland [40] documents the commissioning practices of nine Australian independent presses, most of them MSPs with Indigenous, regional and feminist titles. Commissioning relies on a publisher's networks and author relationships and considers the longevity of the press's backlist. Independents, compared to mainstream publishers, are motivated by "the adventure, drive and excitement of creating quality books" (117).

The acquisition and editorial stages of publishing beg the question of who has the privilege and power to edit whom. Australian critics have dissected the intrusions of white editors into the structure, story and voice of Indigenous authors [26], and practising editors from Indigenous and non-white backgrounds [24] have railed against the dearth of colleagues from non-mainstream communities.

\section{Writers of Difference and Their Publishers}

The "diversity" of Australian publishing outputs is highly contested. Cañas (2017, para. 1) argues that "diversity" is an "in-vogue theme" in Australia's arts, without "a meaningful, committed, resourced, long-term process of shifting existing power-dynamics". It sees through a "white lens [focused on] creating, curating and demanding palatable definitions of 'diversity' but only in relation to what this means in terms of whiteness" (para. 2); we could add: maleness, ableness, etc.

Such palatable diversity is lambasted by Evelyn Araluen [1], Indigenous co-editor of Overland, who condemned the "white-passing privileges" she had received before the age of 25: offers of workshops, readings, prize judging, article commissions and book deals. These were "absolutely traps": "To be allowed to take up so much space when I was ridiculously young and underdeveloped for it is testament to how much the industry wants the right kind of Blak voice for the job of selling Blak culture to a white monied elite."

One study directly asks, "who is publishing diverse books best?" [49], using Goodreads data for the most-popular US books of 2016 and comparing it to authors' public "racial identifiers". Of 163 titles, PRH had the most "diverse" titles, followed by "self-published and independent" presses and the remaining Big Five. Yet this study has serious flaws, as it (a) conflates self-published books with those of independents; (b) sees "diversity" as an author's ethnicity; and c) judges "best" as "largest number in Goodreads' most-popular titles list". Despite the platform's users mostly being "white, college-educated females", the authors claim it "provides a level playing field" with "equitable spacing on its virtual shelves" (209). This ignores the vast difference in promotion budgets between the Big Five and independents [58]. It also doesn't permit the "best" story to be "an authentic story, [which], if mentored and not stolen, if fanned to flame, if made highly visible, can have great currency for those who own it" [44], 18).

Many excluded writers have shared their views on publishing in contemporary articles, yet these pieces focus on perceived market share rather than industry tools to benefit writers like them. In addition, little academic or industry work has 
explored writers' perceptions. Anita Heiss [21] interviewed Australian Indigenous authors in Dhuuluu-Yala, which gathers First Nations writers' opinions of Australian publishing and its workings, although the writers' reflections were not collected in tandem with their presses'. Also, Booth and Narayan [5, 6] interviewed seven young adult (YA) writers about their experiences publishing and promoting their titles.

The UK has been a much-richer source of analysis into WODs and their publishing experiences. One source is Common People: Breaking the Class Ceiling in UK Publishing [48], using interviews of 17 emerging working-class writers as well as publishing professionals. However, writers' contributions created recommendations for government and industry (not day-to-day suggestions for MSPs). Another vital publication, Rethinking "Diversity" in Publishing [46], focussed on the participation of writers of colour in the UK book trade. It found that the primary audience for UK publishing "is white and middle-class. The whole industry is essentially set up to cater for this one audience" (2). Arguments about writing "quality" often disguised staff discomfort at working with non-mainstream voices. In promotion, publishing houses used much-too-limited funds, creativity and awareness in interacting with minority audiences and authors. Many of these flaws are actively addressed by the MSPs I looked at.

But we shouldn't assume that MSPs treat their WODs any better than mainstream publishers. Melbourne-based literary journal The Lifted Brow (TLB) and its micropress Brow Books had regularly been lauded for their non-mainstream publications. However, most of TLB's board and editors resigned early in 2020 when it was revealed that a male editor was accused of having sex with female authors and asking them to conceal it, and the male publisher's response was judged irresponsible $[39,45,55]$.

\section{Theory}

This research holds that publishing is a prime facilitator of access to the public sphere, a space mediating between state and society where citizens can share opinions and debate ideas relevant to all [18]. Later theorists have expanded the original concept beyond property-owning elites to include non-mainstream groups. These may influence "the" public sphere or organise themselves as "counter-" or "little public spheres" that impact specific communities [17, 22]. Yet there are limitations to both variants: an idea's circulation in a sphere may not impact that sphere's participants, nor must individual spheres be open to dialogue with each other or with the mainstream [12].

The connections between the public sphere, media and democracy are a truism, but few scholars have explicitly stated that publishing may also impact the public sphere. Murray [35] uses her monograph's title-The Digital Literary Sphere-to link Habermas' idea with the modern book trade. Further, Bhaskar [2] professes publishing's centrality to any public sphere: it "carries forward our sciences and powers our culture. Publishing isn't a passive medium; it is a part of our lives and societies, shaping them, guiding them, sometimes even controlling them" (5). 
My focus on micro- and small presses is based on my understanding that they contribute to Hawthorne's [20] "bibliodiversity". Parallel to biodiversity, this is the wealth of voices, languages, environments and cultures represented in the book industry; the greater the bibliodiversity, the more stable the publishing ecosystemand the world at large.

This research explored how MSPs, in practising bibliodiversity, enable the expression of silenced voices-or voice. Nick Couldry's formulation [11], 1) is from communication for social change, considering voice both a value and a process through which human beings "give an account of themselves and of their place in the world". As value, it aids expressions in support of human life, resources and organisations, opposing neoliberal political and market processes. As process, voice "is an irreducible part of what it means to be human" (vi). Voice is grounded in social structures; permits reflexivity and agency; is historically embodied; requires material form; and can be undermined by rationalist beliefs. An individual's voice only exists and is respected if they recognise their ideas in group decisions, which can manifest as inclusive social change.

Couldry [11] considers that voice needs narrative resources, where the narrative is sustained by the speaker's lived reality; narrative strategies, which link one's voice to a collective narrative; and spaces for expression, as "people need first to be visible before they can be recognized as having voice" (130, original emphasis). Successfully disseminating voice also requires frames that allow "new types of exchange, new terms of mutual recognition" (147): in publishing, this implies reinventing the role of publishers, distributors, bookshops, libraries, festivals and reviewers.

Three other concepts delimit who may have voice. Olson [38] wrote of the silences of those whose "work [is] aborted, deferred, denied", overshadowed, censored or "physically silenced by governments" (8-9). Worse are "silences where the lives never came to the writing ... those whose waking hours are all struggle for existence; the barely educated; the illiterate; women" (10). The second is by Nguyen [36], who hopes he and other Asian-Americans attain "narrative plenitude", hearing many voices like their own, rather than the current "economy of narrative scarcity, in which we feel deprived and must fight to tell our own stories and fight against the stories that distort or erase us" (para. 5). And finally, before naming someone as voiceless or voice-less, one should ask, "Who does the naming? Who is being named? What difference does it make?" [30], 2).

\section{Methodology}

My chosen methodologies-mixed-method case studies using interviews and limited participatory observation-have been used previously in publishing studies: Childress' Under the Cover [10] used all three and was the only example I found which considered a book's press and its author. His time at Counterpoint Press was also the model for my volunteering with the MSPs in my study. Interviews with publishers are well-established-Thompson's [53] Merchants of Culture used 280 interviews with UK and US publishers-but interviews with authors are rarer (see above). 
The MSPs chosen for study self-identified as publishers of WODs on their websites. They are:

- Spinifex Press [51] a radical feminist press run by Susan Hawthorne and Renate Klein since 1991. With around 235 titles in print, it engages with feminist, lesbian and political issues, publishing "innovative and controversial books with an optimistic edge"; and

- Wild Dingo Press (WDP) [59-60] a micro-press founded by Catherine Lewis in 2010, with 36 titles in print. It shares "the rich cultural output and traditions of those oft-discussed but denied a voice [and gives] control over representation back to the people affected".

My core research was conducted through structured interviews with MSP staff and authors. Each press was asked to suggest two workers to participate and to share my invitation email with their WODs. In practice, both presses pre-selected authors, who I then asked if my research aims resonated with them; this allowed them to selfdefine as a WOD. Staff could provide their name and that of their press, or participate anonymously. All authors are referred to by pseudonyms.

I had offered in-person volunteering to each press, but it only eventuated as a fiveday visit to Spinifex. I interviewed the co-publishers, attended events and proofed work in progress, recording each day's tasks in a templated log. With WDP, I proofread educational collateral from my home.

\section{Results and Discussion}

Nine interviews were conducted in-person or via Zoom, Skype or phone (eight individual interviews, plus Spinifex's co-publishers were interviewed jointly). Three staff agreed that they and their press could be named: Catherine Lewis, WDP publisher, and Susan Hawthorne and Renate Klein, Spinifex co-publishers. All three were interviewed for at least two hours, as was one author, who also supplied written responses. Other interviews lasted 40-60 minutes.

\section{Publishers' Principles and/as Praxis}

It would be impossible to overstate the strength of the two presses' motivations or the degree of alignment between principles, practice and strategically publishing silenced voices. Indeed, both publishers' "business as usual" incorporated strategies that support WODs, so they had difficulty disaggregating their normal tactics from pro-voice activities. Both Spinifex and WDP, like Ramdarshan Bold's presses, are driven by passion; this also directs manuscript selection [40]. Catherine Lewis (WDP) understands the environmental, intellectual and social impact of publishing a title, and says, "A book is not just a sausage ... it needs to be sort of sacralised ... Publishing is like a sacred duty." Spinifex titles are chosen according to the press's feminist principles, aiming to spark public discussion and growth: "people can 
change, men can change. And so we really hope that our books actually contribute to social change" (Renate Klein, co-publisher).

Principles influence more than acquisition strategies. Spinifex and WDP: (a) proactively hire staff who uphold and represent the press's values; (b) prioritise relationships and an ethical work environment for staff, freelancers and printers; (c) give all authors final say on their books' text and (for Spinifex) cover, not publishing unless the author approves; and (d) take risks and stay flexible to achieve their goals (e.g. Spinifex publishing a man's book on radical feminism).

\section{Publishing Writers of Difference}

One Spinifex title provides a detailed example of publishing WODs. Karu: Growing up Gurindji is about the traditional child-rearing practices of Gurindji women, from the Northern Territory's southern Victoria River. Three senior Gurindji women, Wadrill, Yamawurr and Ngarnjal [56], with nine others, shared stories which were translated by their long-time collaborator, Felicity Meakins. The book has text in Gurindji and English, plus photos of medicine plants and the community's paintings. QR codes access recordings of the book's stories in Gurindji. Meakins pitched the manuscript via email; the Gurindji women wanted to do the book because "their work is not taken seriously when they go to hospital to have babies" (Susan Hawthorne, co-publisher). Hawthorne went on, "I thought it was wonderful to be able to do this book because it ties in with our themes of women and of reproduction. Women's culture, traditional culture, ecology, all of that."

Publishing Karu deployed numerous strategies so the Gurindji women could authentically express their stories: a translator who collaborated with them over two decades; a bilingual text supplemented by multimedia; external copy-editing of the Gurindji; and images and artwork providing community context. These offer variations to both Stewart's suggestions and standard publishing practice [50], yet all are effective. It also shows voice operating as a value (Spinifex's respect for Gurindji stories) and a process (by facilitating the elders' voices).

In aiming to amplify voices and stories that are valuable or ignored, neither press chooses authors or topics because of publishing fads or a "diversity checklist": it disrespects an author to issue low-quality work just because they represent a (currently) trendy group and will definitely sell (per Araluen's critique). Rigorous editing shows regard and lets the author "have the best book possible" (Hawthorne, in line with [40]). For Lewis, "if I just start throwing any old story out there, but it's not a good quality, that'll count against [all] the people I publish who are ... disenfranchised voices. ... So I'm letting down my disenfranchised voices of the future".

One difference arose around sensitivity readers, "hired by editors to ensure that characters from [their shared] marginalised background are represented correctly" ([57], para. 12, original emphasis). This description criticises the possible normative function of these readers, linked to Cañas' "palatable diversity", although sensitivity readers are generally perceived more benignly and their use is becoming an industry standard. For Lewis, this recent uptake "just shows you how lagging behind most 
publishing must be". For Hawthorne, though, they are superfluous: "Any good editor should not need a sensitivity reader or else they're not an editor worth paying."

\section{Publishers Play the Long Game}

Both Spinifex and WDP hold a long-term commitment to social change. Throughout Spinifex's 30 years and WDP's 10 years of operation, they have been dedicated to publishing significant voices and perspectives to initiate, enrich or advance political developments. Again, this MSP behaviour is well-documented [41]. Hawthorne acknowledged that diversifying the voices in Australia's publishing and public sphere is "rarely fast ... we hope that our books will still be around in 50 years or 100 years". This long-term vision is only feasible because WDP and Spinifex set such a high bar for quality in writing, editing and book production, and because their publishing often responds to distressingly evergreen issues (e.g. refugee rights, male violence).

A key example is Lewis' highly engaged process of publishing her first book, The Rugmaker of Mazar-e-Sharif [32-33]. After protesting for refugee rights at the Woomera detention centre, Lewis was introduced to Najaf Mazari, an Afghan who had been detained there. "We talked over litres and litres of green tea at his shop. He absolutely trusted ... I wanted to tell his story to the world ... to maybe help change Australian hearts and minds." Robert Hillman, a biographer, was commissioned to write Mazari's story, as Mazari's English was quite limited. "Robert just sat with Najaf for hours, over very many weeks, and he recorded his voice." Hillman wrote the manuscript, "and we got someone to read each chapter so that Najaf could listen to it because ... he could sort of understand the heard word much better. ... we sat in his rug shop for many, many hours, through 18 months ... we got it checked with Afghan academics to make sure everything was factually $100 \%$ correct, we even had it checked with his old case officer from [the] Immigration Department". Lewis and her partner edited the text, "and it is the most authentic representation of his voice. Everybody says so, including Najaf and his family". The book was "a massive bestseller because it was the first full-length account of the modern refugee in [a] detention centre". It has sold an extraordinary 40,000 copies and was adopted on numerous textbook lists.

This sensitive editorial practice shows WDP collaborating carefully with its authors, not only to facilitate the access of low-English and low-literacy writers to publication (cf. Butler), but to enhance the quality of their work and the clarity of their voice. With attractive, solidly edited books in hand, both presses can act unconventionally: only letting their titles go out of print when they lose the rights, and continuing to promote backlist in their catalogues, newsletters and social media. (After 2020's Black Lives Matter protests, Spinifex listed an Indigenous-authored book from 2002 in an academic newsletter.) Compared to the standard 6-week book promotion, ongoing publicity for a backlist title is more likely to create and maintain the visibility required to catalyse voice.

And finally, both Spinifex and WDP emphasised their strong, sincere, longlived connections with nearly all their authors, reflecting Ramdarshan Bold's [42] 
findings. With Lewis' authors, it's an affiliation almost as "close as family" that "goes on for years". This deeper bond also has higher stakes: "if, for any reason, there's a loss of trust, that's very complicated", and trust issues must be considered in "the nature of [working with] disenfranchised voices" (Lewis). Her refugee and immigrant authors may have limited English, have sometimes left countries where trust is hard-earned, and often know little or nothing of Australian business/publishing norms. To avoid unrealistic expectations about timelines, readership and royalties, Lewis communicates simply, clearly and frequently with her authors (through an interpreter if needed). Communicating well with all collaborators shows commitment to promoting voice externally and within the publishing house.

\section{Authors and Their Presses}

Overall, all four authors interviewed were very pleased with their publishers, giving unstinting compliments for the relationship, staff, editorial, design and overall publishing process. Each writer's current publisher compared favourably with their previous small/mainstream houses.

One author had such a good relationship with her press, they jointly published one title (she published the p-book, the press issued the e-book). Helen's press "shared the same vision as me, that these stories needed to be heard because they make up the rich tapestry that is Australia today". Abigail's process was "a much more intimate experience than any of the [previous presses].... And I felt that [the publisher] really cared about the manuscript in a way that I hadn't had before". Gloria's publisher "took a risk, they took a punt. Only because they were interested in difference!"

Further, all four authors valued their presses' ongoing consultation on topics from metaphor choice to jacket images to prize nominations, and appreciated their concerted efforts to ensure authors' ownership of the cover and published text. Three WODs applauded their presses' long-term commitment: "They keep you in their list forever, unlike big publishers" (Gloria).

Each author was emphatic that her work maintained its integrity in the publishing process; that the press engaged with all facets of their identity and ideas; and that both books and promotion were an adequate representation of their original vision. These comments indicate that WDP and Spinifex have successfully supported their authors' reflexivity and agency in transmitting their voice. Unsurprisingly, all four WODs would recommend their press to other WODs or mainstream writers. Two writers have already done so, but one expressed serious reservations about WDP's co-publishing model, in which authors are 50-50 partners for both costs and royalties. This author would recommend WDP to emerging writers only if they weren't obliged to co-publish, and also noted that co-publishing was possibly not appropriate for authors used to being paid for their work.

As negatives, "the big disadvantage — as I'm sure you'll know about the small publishing houses - is a) their distribution and b) their PR abilities" (Abigail). All authors called out their titles' limited presence in bookshops and reviews, and their poor access to media and festivals. Two mentioned low advances, but knew this 
resulted from low budgets rather than poor practice [58]. In a similar vein, Gloria stated, "I think their strategies are very strong, but ... They're up against so much, so many variables... whether they succeed or not is another story."

\section{Authors' Suggested Publishing Strategies}

The authors' strategies focused primarily on acquisition and marketing/publicity. They urged publishers to accept unsolicited manuscripts, respond to every submission, and allow authors to vary their style (rather than expecting reruns of previous successes). The WODs suggested publishers review promotion strategies with the book's author, and fund authors' attendance at festivals and events. Authors also encouraged large publishers to have a dedicated imprint or department for diverse narratives, part of showing leadership in regard to publishing plural voices.

The WODs also advised conceptual modifications that would see publishers better enable their voice in the book industry. These are encapsulated in Gloria's sixpoint plan for Australian publishers" "wholehearted engagement" with writers and readers of difference:

1. Know them ... the genuine interest in the other ... in a literature that is plural and that grows! Please do not to make all your writers sound like you or white or Anglo-European. 2. Give them a chance to be heard. 3. Sustain them by investing in them long-term in terms of money, creative development[,] support and time. 4. Educate your readers on how to listen to [them]! 5. Educate yourself; educate your literary palate. 6. Re-think your idea of "the market”: publishing is not just a business. (original emphasis)

\section{Limitations and Further Research}

Coronavirus limited my research scope, yet my reduced number of interviewees were very generous with their views, and constitute a reasonable representation of the very few publishers that self-define as supporting voice-creators in Australia (my research identified nine). Of those participants, all are women, and the great majority white and over 60. All spoke from long publishing experience, but their views will differ vastly from those of young, emerging, mostly digital writers.

Two potential issues arose related to author recruitment. Both houses directly contacted authors they thought could make a good contribution. This carries the risk the publishers chose only authors they knew would speak well of them, but I believe good author-press relationships are the norm for both Spinifex and WDP. This may also mean the publishers could trace statements in my research to particular writers; I have upheld author confidentiality, sometimes at the cost of detail.

These limitations signpost further research. Similar studies can be undertaken in other publishing territories, ideally with more presses and authors, or in other book-industry sectors (e.g. libraries). Studies could focus on strategies that benefit one kind of WOD; investigate tactics used for one author in multiple territories; or incorporate quantitative comparisons between techniques, investments and sales of 
WODs' books and rights. More complex research could trace the impacts on the literary and public spheres once a WOD has expressed their voice through publishing.

\section{Conclusion}

Klein, Hawthorne and Lewis founded their presses to amplify under-represented WODs: in Spinifex's case, radical feminists; in WDP's, Australia's disempowered and disenfranchised. Their "sacred duty" guided their publishing strategies in similar directions, in which authors are never reduced to a commodity (as seen too often in mainstream publishing). Their authors suggested their own strategies and offered strong positive responses about their small-press experiences, celebrating the nontraditional strategies around commitment, time, quality, integrity, risk, relationships and long-term publicity; they also acknowledged the traditional bugbears (distribution and promotion).

Through their interrelated principles and practices, WDP and Spinifex fulfil many of Couldry's requirements for facilitating the voice of writers of difference: they create visibility; respect and act on an author's voice; manifest it in material form (a book); strengthen their agency and reflexivity; and work to develop narrative resources, strategies and spaces to strengthen their message in the public sphere. Their commitment to social change can be stated thus: "The editor [or publisher] is in service to the writer; the editor and the writer are in service to the book; the book is in service to an entire community" [47], 147). Spinifex and Wild Dingo demonstrate that MSPs can uplift neglected voices and that their publishing strategies deserve scrutiny as political actions, thus supporting my contention that the relationship between social change and the small-press sector merits greater attention in publishing studies and communication for social change.

\section{References}

1. Araluen E (@evelynaraulen). In the interest of transparency and community accountability I'd like to talk about some of the white passing privileges I've... [first Tweet in thread]. 2020. https://twitter. com/evelynaraluen/status/1293521416701108230.

2. Bhaskar M. The content machine: towards a theory of publishing from the printing press to the digital network. London: Anthem Press; 2013.

3. Binks D. We read to know we are not alone: examining the lack of LGBTQI characters in Australian youth literature. Kill Your Darlings. 2014. www.killyourdarlings.com.au.

4. Bobis M. Subversive translation and lexical empathy: pedagogies of cortesia and transnational multilingual poetics. In: Martín-Lucas B, Ruthven A, editors. Narratives of difference in globalized cultures. Cham: Palgrave Macmillan; 2017. p. 13-35.

5. Booth E, Narayan B. 'Don't talk about the gay character': barriers to queer young adult fiction and authors in schools and libraries. EnglAust. 2018;53(2):40-8.

6. Booth E, Narayan B. Towards diversity in young adult fiction: Australian YA authors' publishing experiences and its implications for YA librarians and readers' advisory services. J AustLibrInfAssoc. 2018;67(3):195-211. 
7. Butler N. The publishing of Australian writers with educational and social class disadvantage. Master's thesis, University of Melbourne. 2019.

8. Cahill M. Who is lobbying for migrant writers? Sydney Review of Books. 2015. https://sydneyrevi ewofbooks.com.

9. Cañas T. Diversity is a white word. Arts Hub. 2017. www.artshub.com.au.

10. Childress C. Under the cover: the creation, production, and reception of a novel. Princeton: Princeton University Press; 2017.

11. Couldry N. Why voice matters: culture and politics after neoliberalism. London: Sage; 2010.

12. Dreher T. Speaking up or being heard? Community media interventions and the politics of listening. Media Cult Soc. 2010;32(1):85-103. https://doi.org/10.1177/0163443709350099.

13. Driscoll B, Fletcher L, Wilkins K, Carter D. The publishing ecosystems of contemporary Australian genre fiction. CreatInd J. 2018;11(2):203-21. https://doi.org/10.1080/17510694.2018.1480851.

14. Driscoll B, Fletcher L, Wilkins K. Women, Akubras and ereaders: romance fiction and Australian publishing. In: Mannion A, Stinson E, editors. The return of print? Contemporary Australian publishing. Clayton: Monash University Publishing; 2016. p. 67-87.

15. Evershed N. Australia's newspaper ownership is among the most concentrated in the world. The Guardian. 2020. www.theguardian.com.

16. Flood A. \#Publishingpaidme: authors share advances to expose racial disparities. The Guardian. 2020. www.theguardian.com.

17. Fraser N. Rethinking the public sphere: a contribution to the critique of actually existing democracy. Social Text. 1990;25(26):56-80.

18. Habermas J. The public sphere: an encyclopedia article. In: Durham MG, Kellner DM, editors. Media and cultural studies: keyworks. Malden: Blackwell; 2006.

19. Hamilton C. Don't look back: contemporary independent magazine publishing beyond the digital divide. In: Stinson E, editor. By the book? Contemporary publishing in Australia. Clayton: Monash University Publishing; 2013. p. 43-58.

20. Hawthorne S. Bibliodiversity: a manifesto for independent publishing. North Melbourne: Spinifex; 2014.

21. Heiss AM. Dhuuluu-yala (To talk straight): publishing indigenous literature. Canberra: Aboriginal Studies Press; 2003.

22. Hickey-Moody A. Youth agency and adult influence: a critical revision of little publics. Rev EducPedag Cultural Stud. 2016;38(1):58-72. https://doi.org/10.1080/10714413.2016.1119643.

23. Hoge R. Open the gates for stories about disability. ABC News. 2013. www.abc.net.au.

24. Ibrahim H, Grace L-P. We need diverse editors. Djed Press. 2018. https://djedpress.com/2018/01/ 29/we-need-diverse-editors.

25. Jemisin NK (@nkjemisin). Important to watch the \#PublishingPaidMe hash, writers and esp BIPOC writers. For the curious, as I recall, my advances were: [first Tweet in thread]. 2020. https://twitter. com/nkjemisin/status/1269413383993950208.

26. Jones JA. Black writers, white editors: episodes of collaboration and compromise in Australian publishing history. North Melbourne: Australian Scholarly Publishing; 2009.

27. Kon-yu N. 2018. In the skin of the other: diversity and the Australian publishing industry. Text 53 (Oct):1-13 [sic]. www.textjournal.com.au.

28. Kwaymullina A. Privilege and literature: three myths created by misdiagnosing a lack of indigenous voices (and other diverse voices) as a 'diversity problem'. LoveOzYA. 2016. http://loveozya.com.au.

29. LeClerc T. The privilege of common sense. Overland. 2020. https://overland.org.au.

30. Mamdani M. The politics of naming: genocide, civil war, insurgency. London Review of Books. 2007; 29(7):5-8. www.lrb.co.uk.

31. Marlow K. Indigenous publishing: telling and owning our stories. NITV. 2016. www.sbs.com.au.

32. Mazari N, Hillman R. The Rugmaker of Mazar-e-Sharif. Elsternwick: Insight Publications; 2008.

33. Mazari N, Hillman R. The Rugmaker of Mazar-e-Sharif. Cheltenham: Wild Dingo Press; 2011.

34. McGaughey J. Why Australian YA needs more Torres Strait Islander writing. Kill Your Darlings. 2020. www.killyourdarlings.com.au.

35. Murray S. The digital literary sphere: reading, writing, and selling books in the internet era. Baltimore: Johns Hopkins University Press; 2018.

36. Nguyen VT. Asian-Americans need more movies, even mediocre ones. The New York Times. 2018. www.nytimes.com.

37. Nielsen BookScan. Australian Book Market (ABM), YTD to Q3 2019 (30-Dec-2018 to 07-Sep2019). 2019. 
38. Olson T. Silences. London: Virago; 1980.

39. Overington C. Tales of sexual misconduct push the lifted brow close to the edge. The Australian. 2020. www.theaustralian.com.au.

40. Poland L. Independent Australian publishers and the acquisition of books. J Aust Stud. 1999;23(63):110-8, 97-98. https://doi.org/10.1080/14443059909387540.

41. Poland L. Survive and succeed: independent Australian publishers. Publishing Studies. 1999;7:17-30.

42. Ramdarshan Bold M. Standing in the shadow of giants: publishing in the Midlands and North of England. Logos. 2015;26(4):37-50.

43. Ramdarshan Bold M. An 'accidental profession': small press publishing in the Pacific Northwest. Publ Res Q. 2016;32(2):84-102. https://doi.org/10.1007/s12109-016-9452-9.

44. Rankin S. Soggy biscuit: invisible lives - or the emperor's new social work? Griffith Rev. 2014;44(Winter):11-32.

45. Reeson O. (@OliverReeson). I feel dumb for doing this but as a writer who has published with and been supported by TLB a... [first Tweet in thread; since deleted]. 2020 [updated 2020 Apr 9; cited 2020 Apr 15]. https://twitter.com/OliverReeson/status/1248098265477734400.

46. Saha A, van Lente S. Rethinking "diversity" in publishing. London: Goldsmiths Press. 2020. www. spreadtheword.org.uk.

47. Schotts J. The half-open door: independent publishing and community. In: Ginna P, editor. What editors do: the art, craft, and business of book editing. Chicago: University of Chicago Press; 2017. p 141-148.

48. Shaw K. Common people: breaking the class ceiling in UK publishing. New writing north writing West Midlands, Northumbria University Newcastle; 2020. www.northumbria.ac.uk.

49. Shea N, Mulvihill G, La Bianca Vi, Hanchar A. Who is publishing diverse books best? Publ Res Q. 2018;34(2):207-17. https://doi.org/10.1007/s12109-018-9573-4.

50. Smart R, editor. An introduction to Australian book publishing. 5th ed. Ultimo: Australian Publishers Association; 2012.

51. Spinifex Press. About us. n.d. www.spinifexpress.com.au/About_Us. Accessed 23 Feb 2021.

52. Stewart S. Making evaluative judgements and sometimes making money independent publishing in the 21st century. J Cultural Anal Soc Change. 2018;3(2):10. https://doi.org/10.20897/jcasc/3991.

53. Thompson JB. Merchants of culture: the publishing business in the twenty-first century. 2nd ed. Cambridge: Polity; 2012.

54. Throsby D, Zwar J, Morgan C. 2018. Australian book publishers in the global industry: survey method and results. Macquarie University Department of Economics. 2018. Research Paper No. 1/2017. https://apo.org.au.

55. TLB Society Inc. A message from the board of TLB society Inc. 2020. www.theliftedbrow.com.

56. Wadrill V, Wavehill Yamawurr B, Dodd Ngarnjal T, Meakins F. Karu: growing up Gurindji. Mission Beach: Spinifex Press; 2019.

57. Wasafiri Editor. Beyond benign notions of 'diversity': Sandeep Parmar and Anamik Saha in Conversation. Wasafiri. 2020. www.wasafiri.org.

58. White, T-A. The marketing was crap. Sydney Review of Books. 2017. https://sydneyreviewofbooks. com/essay/the-marketing-was-crap.

59. Wild Dingo Press. Books that stand their ground. 2016a. www.wilddingopress.com.au/about.

60. Wild Dingo Press. Shop for books. 2016b. www.wilddingopress.com.au/shop-for-books.

61. Wood R. On identity. Mascara Literary Review. 2016. http://mascarareview.com.

Publisher's Note Springer Nature remains neutral with regard to jurisdictional claims in published maps and institutional affiliations. 